\title{
Description of Surgery Technique of the Lower Trapezius Transfer with Semitendinosus and Gracilis Tendon Graft for the Treatment of Massive or Irreparable Rotator Cuff Tear
}

Thiago Bernardo Carvallho de Almeida ( $\nabla$ dr.tbca@hotmail.com )

Faculdade de Medicina do ABC https://orcid.org/0000-0002-5708-5450

Luciano Miller Reis Rodrigues

Centro Universitário Saúde ABC. Faculdade de Medicina do BC

Marcel Jun Sugawara Tamaoki

Universidade Federal de Sao Paulo

Luciano Pascarelli

Shoulder and Elbow Department, Rede D'Or São Luiz - Hospital Ifor

Roberto Rangel Bongiovanni

Shoulder and Elbow Department, Rede D'Or São Luiz - Hospital Ifor

\section{Technical note}

Keywords: Lower trapezius transfer, Massive irreparable tear, Hamstring tendons, Rotator cuff tears

Posted Date: November 4th, 2020

DOI: https://doi.org/10.21203/rs.3.rs-100324/v1

License: (c) (1) This work is licensed under a Creative Commons Attribution 4.0 International License.

Read Full License 


\section{Abstract}

Background: The current work describes a surgery technique where the autograft of hamstring tendon (semitendinosus and gracilis) was used as adjuvant in the transfer of the lower trapezius for the treatment of massive or irreparable rotator cuff tear. There is a theoretical advantage that the graft takes a greater footprint area in the greater tuberosity of the humerus corresponding to the infraspinatus, thus recreating the native anatomy more accurately.

Methods: The autograft of hamstring tendon was attached to the lower trapezius through an incision of $4 \mathrm{~cm}$ in the middle third of the scapular spine and transferred to the footprint of the infraspinatus in the greater tuberosity of the humerus, where it is attached through the second incision under the lateral acromial margin.

Result: The patient was examined preoperatively and after 6 months of follow-up, and his pain, according to the Visual Analogue Scale, varied from 8 to 3, the range of motion improved in abduction from $100^{\circ}$ to $120^{\circ}$, external rotation from $30^{\circ}$ to $50^{\circ}$ and flexion from $110^{\circ}$ to $150^{\circ}$. The Shoulder Subjective Value ranged between 60 and $80 \%$ and the Disabilities of the Arm, Shoulder and Hand score went from 45 to 18.3 .

Conclusions: The lower trapezius transfer with autograft of hamstring tendons is a low-cost and relatively reproducible surgical technique with theoretical biomechanical and anatomic advantages that may bring about better function results.

\section{Introduction}

The treatment of massive or irreparable rotator cuff injuries is still a challenge for orthopedists, especially when it comes to young patients due to arthroplasty contraindications $[1,2)$. Such injuries, particularly those with great retraction or fat infiltration, are likely to be irreparable, and in the event of repair, there is a higher rate of re-rupture and poor functional results [3].

The treatment of these irreparable injuries, principally when they are associated with some level of glenohumeral arthrosis, is the reverse arthroplasty; however, this approach is reserved for older patients due to the possible complications brought by the implant in the long run [4]. Therefore, for young and high-demand patients, many techniques have been described with variable results in the past few years. Some examples of these techniques include surgical debridement and partial repair of the injury, superior capsular reconstruction, tenotomy of the long head of the biceps brachii, biodegradable balloon spacers, deltoid muscle flap, and the muscular transfers like the lower trapezius transfer.

The transfer of the lower trapezius (LT) has been indicated for the increase in external rotation in patients with paralytic shoulders with excellent results [5]. Elhassan [5] observed that the lower trapezius has a congruent and synergistic anatomic relation with the infraspinatus muscle regarding the line of pull. In another study, with 33 patients in 2016, the authors showed good results on LT transfer in treatments of 
irreparable rotator cuff tear (RCT) using a calcaneal allograft which was brought down to the infraspinatus footprint [6]. Nevertheless, the authors did not mention the anatomic coverage of the allograft that was used in the greater tuberosity (GT) of the humerus or its relation with the infraspinatus footprint.

In many countries worldwide, the use of allografts is not allowed for legislative reasons, a fact that hinders the reproduction of this technique. Thus, other viable and effective options of grafts as an adjuvant treatment are made necessary. In this context, some authors report the use of autografts instead of the use of the calcaneal tendon in LT transfers. In 2018, Valenti et al. [7] published a work on LT transfer using an autogenous graft of the semitendinosus tendon aiming to prevent the possible complications of the allograft. Good results were obtained in regard to motion range recovery and strength as well as the decrease of pain severity. On the other hand, the authors did not describe the anatomic relation of the graft, its position and coverage in the footprint region of the cuff in the GT of the humerus.

Recent findings on the anatomy of supraspinatus (SS) and infraspinatus (IS) tendons reveal that the SS insertion in the footprint of the GT of the humerus is much smaller than what was believed before, and that this bigger area of GT is substantially occupied by the insertion of the IS tendon [8]. Hence, the need to use a larger graft so that all the native area of the IS can be occupied in the GT of the humerus.

The aim of this study is to describe a surgery technique of the lower trapezius transfer using the hamstring tendon graft (semitendinosus and gracilis) for a greater coverage area in the GT of the humerus. A great advantage of the technique is the use of a larger autograft that allows for a more anatomic reproduction of the insertion of the rotator cuff with better functional results.

\section{Method}

The lower trapezius transfer is a procedure that has been applied since 2018, and it was developed by the shoulder and elbow orthopedic team from the Instituto de Fraturas Ortopedia e Reabilitação, Hospital IFOR, in São Bernardo do Campo, São Paulo, Brazil. Table 1 shows the indications and contraindications for the use of this technique. 
Table 1

Indications and contraindications for lower trapezius transfer

\section{Indications}

- Persistent pain

- Massive RC tear detected by MRI scan

- Goutallier classification $\geq 3$, positive tangent sign

-MR limitations, especially external rotation

- Conservative treatment failure

\section{Contraindications}

- Previous comorbities that hindered the procedure

- Impossibility to follow the post-operative instructions

- Advanced glenohumeral arthrosis

- Age over 65 years

- Subscapularis, deltoid or trapezius insufficiency

$R C$ rotator cuff, $M R /$ magnetic resonance imaging, $M R$ motion range

\section{Surgical technique}

Patients are submitted to general anesthesia and undergo interscalene brachial plexus block. At first, the grafts from the hamstring tendon (semitendinosus and gracilis) are harvested with the aid of a stripper. An antero-medial incision is made over the topography of the insertion on the ipsilateral side of the affected shoulder and a local anesthetic infiltration is performed with $5 \mathrm{ml}$ of ropivacaine. Both tendons are attached with simple suture using absorbable thread (Figs. 1, 2 and 3). Hence, a long graft is obtained, with thickness relatively similar to that of the rotator cuff and width that is compatible with the area of insertion of the infraspinatus tendon [8].

After the graft is prepared for placement, the patient is subsequently repositioned in lateral decubitus for the second stage of the procedure. A sterile surgical skin marker was used to design on the shoulder girdle the main anatomic structures involved (Fig. 4). The first incision is made lengthwise in the middle third of the scapular spine (Fig. 4).

As soon as the lower trapezius tendon is identified right below the subcutaneous tissue, its dissection from the lower border of the scapular spine is carried out (Fig. 5).

A saber-cut incision is then performed over the lateral acromial margin (Fig. 6). Around $5 \mathrm{~mm}$ of the lateral acromion is resected with the aid of a bone chisel $(16 \mathrm{~cm}-10 \mathrm{~mm})$. The approach is conducted between the anterior and medial portions of the deltoid muscle; thus, it is possible to analyze the glenohumeral articulation and the upper portion of the subscapularis tendon (ST). It is important to point out that this access allows for the repair of minor ST tears as well as the performance of the tenotomy of the long head of the biceps tendon whenever it is necessary.

Next, the semitendinosus and gracilis tendon graft is attached to the tendon of the lower trapezius through an incision made between the fibers of the trapezius. The graft then goes through the incision 
and folds, covering around $3 \mathrm{~cm}$ of the LT. Simple sutures are placed at its bottom followed by the use of the Krackow suture technique due to its holding power (Fig. 7).

The graft attached to the LT is transferred with the aid of long forceps under the posterior deltoid muscle. By doing so, the tendon reaches the footprint of the rotator cuff in the greater tuberosity (GT) of the humerus (Fig. 8). The graft repair complied with the coverage area of the infraspinatus tendon in the GT [8] (Fig. 9). The graft fixation is performed with the shoulder held in $60^{\circ}$ of external rotation, $50^{\circ}$ of abduction and maximum tension of the trapezius and the graft. The double-row repair was the technique applied using 4 Linvatec ${ }^{\circledR}$ Super Revo FT anchors (Fig. 9).

\section{Result}

This case involved a 45-year-old patient named C.A.F., a forklift driver, who had been in pain (Visual Analogue Scale (VAS) 8) and had been losing the strength in the left shoulder for 8 years, with significant worsening of the symptoms in the last 6 months prior to his visit. After attempts of treatment with physiotherapy and rehabilitation sessions as well as infiltration therapy, there was no improvement in the clinical status. During the shoulder physical exam, the following was observed: positive Jobe's test; positive infraspinatus test; negative Gerber's lift-off test; positive lag sign at 90 degrees. Regarding motion range: abduction, $100^{\circ}$; flexion, $110^{\circ}$; external rotation, $30^{\circ}$; internal rotation to L5. When the X-ray tests were evaluated, a rise of the humeral head in the anteroposterior incidence of the shoulder could be seen. MRI scan images revealed a massive injury in the supra- and infraspinatus tendons with a significant fatty degeneration (Fig. 10).

The patient underwent transfer of the lower trapezius with autogenous hamstring tendon graft (semitendinosus and gracilis).

During his six-month follow-up evaluation, the patient showed a considerable decrease in pain severity (score rate 3 , mild) according to the VAS. His motion range improved as follows: abduction, $120^{\circ}$; flexion, $150^{\circ}$; external rotation, $50^{\circ}$. No changes in the internal rotation could be observed. The Shoulder Subjective Value (SSV) ranged between 60 and $80 \%$ and the Disabilities of the Arm, Shoulder and Hand (DASH) score went from 45 to 18.3 (Fig. 11).

\section{Discussion}

The results obtained from RCT treatments have been improved due to recent breakthroughs in surgical techniques and the development of new surgical instruments. However, failure rates reach $40 \%$ when it comes to massive injuries [9]. Actually, some authors report that up to $30 \%$ of all RCTs can be classified as irreparable, given their dimension associated with the severe muscle degeneration $[10,11]$. 
Painful and dysfunctional shoulders in active working individuals with irreparable injuries in the rotator cuff (RC) are a major challenge. Reverse shoulder arthroplasty (RSA) is a valuable option in chronic treatments; nevertheless, in young active arthrosis-free patients, the limited lifespan of RSA and the considerable potential for complex revisions after the event of infections or instability are great concerns [12-15].

Muscle transfers for these injuries are a feasible alternative with promising results, and the most vastly studied transfer is the great dorsal to the tuberosity [16]. However, the results are not reproducible or constant $[17,18]$, so other options have been tried and assessed, and today the literature encourages the use of the LT in muscle transfers, especially in the treatment of brachial plexus paralysis and massive rotator cuff tears. Biomechanical evidences show that LT transfers are more anatomical than those of the latissimus dorsi (LD) with better outcomes for abduction, flexion and external rotation $[19,20]$.

According to Burkhart [21], in order to establish the balance in the glenohumeral articulation for any arm position, there must be a balance between force and moment. Biomechanical studies reveal that LT transfer is more effective in the restoration of this balance [22].

For the past few years, there have been many descriptions of different techniques for lower trapezius transfer, particularly in regard to the type of graft used in its fixation in the greater tuberosity of the humerus. Valenti et al.[7] used only the folded semitendinosus tendon with an extension band of $20 \mathrm{~cm}$ attached to humeral head in two different ways: the first with cortical button (Zip Tight $\circledast$ ) and the second with anchors. There is no reference in the literature regarding the right placement of the graft insertion.

Some studies on the biomechanics of shoulder muscle transfers are available in the literature. Omid et al. [22] measured the forces applied to the humeral head during rotations, at neutral and humeral head apex positions in shoulders with rotator cuff injury and compared LT and LD transfers. The authors observed that the LT transfer was more effective when it came to restoring values closer to those of an intact rotator cuff. Reddy et al. [20] measured muscular tension in 3 different positions of the arm comparing LT and LD transfers: (1) supraspinatus footprint; (2) infraspinatus footprint; and (3) the teres minor footprint. However, no anatomical relation between the width of the graft and the insertion area to be occupied could be found in the literature. On the other hand, some anatomical articles show that the insertion area of the infraspinatus occupies $20 \mathrm{~mm}$ of width in the greater tuberosity [8] which theoretically shows the importance of having a graft that is compatible with this size.

The technique here described searches for a better placement for the reinsertion of the semitendinosus and gracilis graft for the original footprint of the IS tendon in the greater tuberosity of the humerus. The graft is wider, and it is able to cover all the insertion of the IS in the greater tuberosity of the humerus, as shown by Mochizuki et al [8].

Whenever a tendon is submitted to constant elongation and remains at the same length for longer periods, the corresponding force will progressively decrease [23]. This phenomenon is known as static 
force relaxation. This is the reason why the tendons associated with the semitendinosus were used here so that their resistance could be increased.

Theoretically, this technique offers two advantages. The first one is anatomical due to the capacity of a better coverage of the native footprint; the second is the creation of a more physiological vector and the improvement of the biomechanical resistance. Nevertheless, these advantages should be more thoroughly investigated in future studies.

\section{Conclusion}

The lower trapezius transfer with autograft of knee flexor tendons is a low-cost and relatively reproducible surgical technique with theoretical biomechanical and anatomic advantages that may bring about better functional results.

\section{Abbreviations}

DASH: Disabilities of the Arm Shoulder and Hand; GT: greater tuberosity; IS: infraspinatus; LD: latissimus dorsi; LT: lower trapezius; RC: rotator cuff; RCT: rotator cuff tear; RSA: reverse shoulder arthroplasty; SS: supraspinatus; SSV: Shoulder Subjective Value; ST: subscapularis tendon; VAS: Visual Analogue Scale;

\section{Declarations}

\section{Acknowledgements}

Not applicable

\section{Author's contribution}

TBCA: Main author, bibliographic review, preparation of the article. LMRR: bibliographic review. MJST: bibliographic review, proofreading. LP: bibliographic review. RRB: bibliographic review. All of the authors have read and approved the final manuscript.

\section{Funding}

This study did not receive any specific grant from funding agencies in the public, commercial, or not-forprofit sector.

\section{Availability of data and materials}

All data generated or analyzed during this study are available in this article. 


\section{Ethics approval and consent to participate}

This study was conducted in accordance with the Helsink Declaration and approved by the Research Ethics Committee of Hospital IFOR under number 4203.149. The patient included in this study gave his informed consent.

\section{Consent of publication}

Written informed consent for publication of the clinical details and/or clinical images was obtained from the patient. A copy of the consent form is available for review by the Editor of this journal

\section{Competint interests}

The authors declare that they have no competing interest.

\section{References}

1. Yoo JC, Ahn JH, Yang JH, Koh KH, Choi SH, Yoon YC. Correlation of arthroscopic repairability of large to massive rotator cuff tears with preoperative magnetic resonance imaging scans. 2009;25:573-82.

2. Alidousti A, Mirzaee F, Bahramian F, Zafarani Z, Mirzaei N, Aslani Repair of massive and irreparable rotator cuff tear using arthroscopic method. J Lasers Med Sci. 2018;9:168-76.

3. Galatz LM, Ball CM, Teefey SA, Middleton WD, Yamaguchi K. The outcome and repair integrity of completely arthoscopically repaired large and massive rotator cuff tears. J Bone Joint Surg Am. 2004;86:219-24.

4. Werner CMI, Steinmann PA, Gilbart M, Gerber C. (2005) Treatment of painful pseudoparesis due to irreparable rotador cuff dysfunction with Delta III reverse-ball-and-socked total shoulder prosthesis. J Bone Joint Surg Am. 2005; 87:1476-86.

5. Elhassan B. Lower trapezius transfer for shoulder external rotation in patients with paralytic shoulder. J Hand Surg Am. 2014;39:556-62.

6. Elhassan BT, Wagner ER, Werthel JD. Outcome of lower trapezius transfer to reconstruct massive irreparable posterior-superior rotator cuff tear. J Shoulder Elbow Surg. 2016;25:1346-53.

7. Valenti P, Werthel J-D. Lower trapezius transfer with semitendinosus tendon augmentation. Obere Extrem. 2018;13:261-8.

8. MochizukiT, Sugaya H, Uomizu M, Maeda K, Matsuki K, Sekiya I, et al. Humeral insertion of the supraspinatus and infraspinatus: new anatomical findings regarding the footprint of the rotator cuff: surgical technique March 200 The J Bone Joint Surg Am. 2009; 91 Suppl 2 Pt 1: 1-7.

9. Chung SW, Kim JY, Kim MH, Kim SH, Oh JH. Arthroscopic repair of massive rotator cuff tears: outcome and analysis of factors associated with healing failure or poor postoperative function. Am 
J Sports Med. 2013;41:1674-83.

10. Warner JJ. Management of massive irreparable rotator cuff tears: the role of tendon transfer. Instr Course Lect. 2001; 50:63-71.

11. Neri BR, Chan KW, Kwon YW. Management of massive and irreparable rotator cuff tears. J Shoulder Elbow Surg. 2009;18:808-18.

12. Boileau P, Melis B, Duperron D, Moineau G, Rumian AP, Han Y. Revision surgery of reverse shoulder arthroplasty. J Shoulder Elbow Surg. 2013;22:1359-70.

13. Farshad M, Gerber C. Reverse total shoulder arthroplasty: from the most to the least common complication. Int Orthop. 2010;1075-82.

14. Gerber C, Canonica S, Catanzaro S, Ernstbrunner L. Longitudinal observational study of reverse total shoulder arthroplasty for irreparable rotator cuff dysfunction: results after 15 years. J Shoulder Elbow Surg. 2018;27:831-8.

15. Zumstein MA, Pinedo M, Old J, Boileau P. Problems, complications, reoperations, and revisions in reverse total shoulder arthroplasty: a systematic review. J Shoulder Elbow Surg. 2011;20:146-57.

16. Tauber M, Moursy M, Forstner R, Koller H, Resch H. Latissimus dorsi tendon transfer for irreparable rotator cuff tears: a modified technique to improve tendon transfer integrity: surgical technique. $J$ Bone Joint Surg Am. 2010;92(Suppl 1 Pt 2):226-39.

17. Gerber C, Rahm SA, Catanzaro S, Farshad M, Moor BK. Latissimus dorsi tendon transfer for treatment of irreparable posterosuperior rotator cuff tears: long-term results at a minimum follow-up of ten years. J Bone Joint Surg Am. 2013;95:1920-26.

18. El-Azab HM, Rott O, Irlenbusch U. Long-term follow-up after latissimus dorsi transfer for irreparable posterosuperior rotator cuff tears. J Bone Joint Surg Am. 2015;97:462-9

19. Clouette J, Leroux T, Shanmugaraj A, Khan M, Gohal C, Veillette C, et al. The lower trapezius transfer: a systematic review of biomechanical data, techniques, and clinical outcomes. J Shoulder Elbow Surg. 2020;29:1505-12.

20. Reddy A, Gulotta LV, Chen X, Castagna A, Dines DM, Warren RF, et al. Biomechanics of lower trapezius and latissimus dorsi transfers in rotator cuff-deficient shoulders. J Shoulder Elbow Surg 2019;28:1257-64.

21. Burkhart SS. Fluoroscopic comparison of kinematic patterns in massive rotator cuff tears: a suspension bridge model. Clin Orthop Relat Res. 1992:144-52.

22. OmidR, HeckmannN, Wang L, McGarry MH, Vangsness Jr CT, Lee TQ. Biomechanical comparison between the trapezius transfer and latissimus transfer for irreparable posterosuperior rotator cuff tears. J Shoulder Elbow Surg. 2015;24:1635-43.

23. Woo SLY, Smith BA, Johnson GA. Biomechanics of knee ligaments. In: Fu FH, Harner CD, Vince KG. Knee Surgery. Baltimore: Williams \& Wilkins, 1994. p.155-72.

\section{Figures}




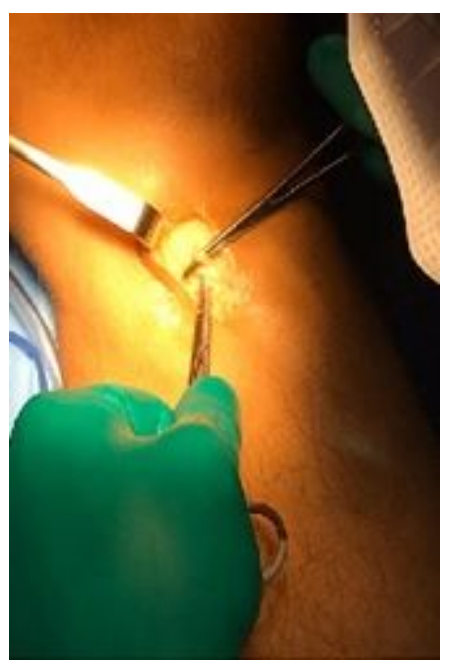

\section{Figure 1}

Semitendinosus and gracilis tendon harvesting.

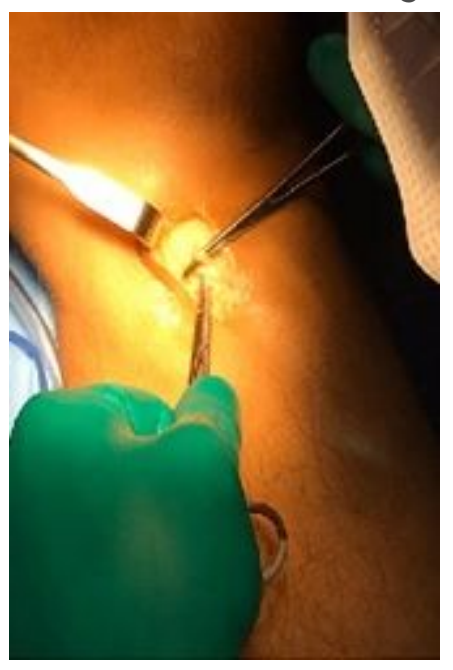

\section{Figure 1}

Semitendinosus and gracilis tendon harvesting.

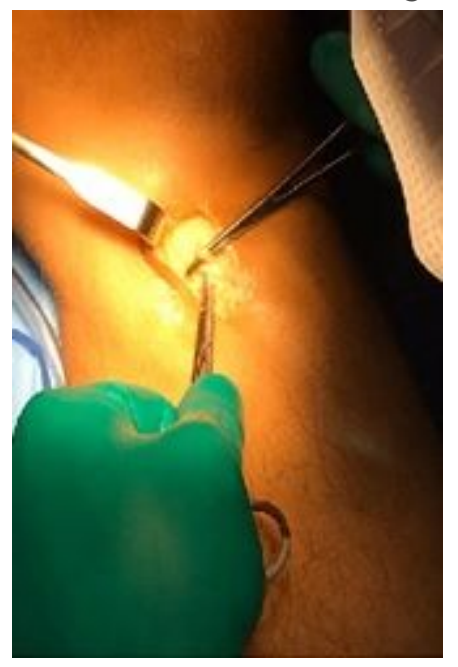


Figure 1

Semitendinosus and gracilis tendon harvesting.

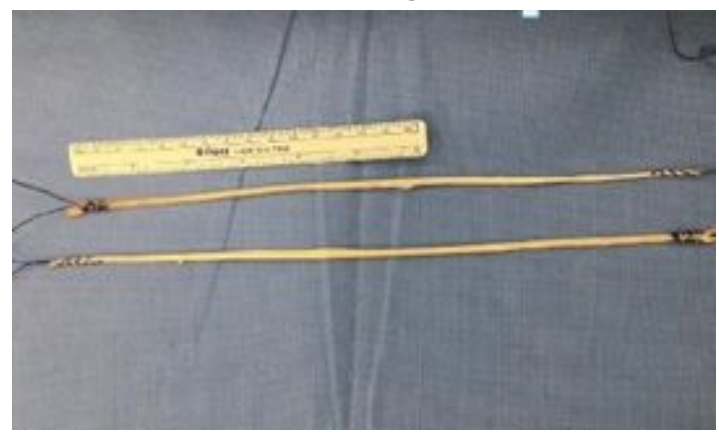

\section{Figure 2}

The grafts are cleaned and verified.

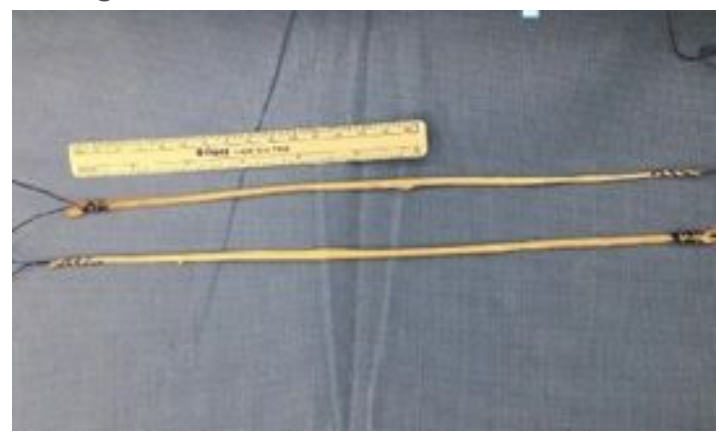

\section{Figure 2}

The grafts are cleaned and verified.

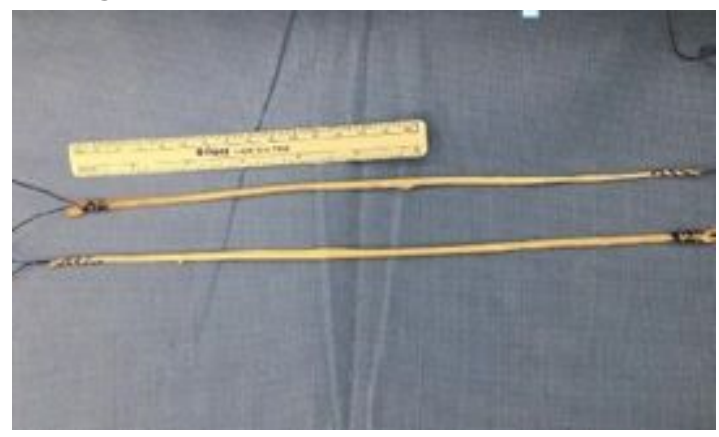

Figure 2

The grafts are cleaned and verified.

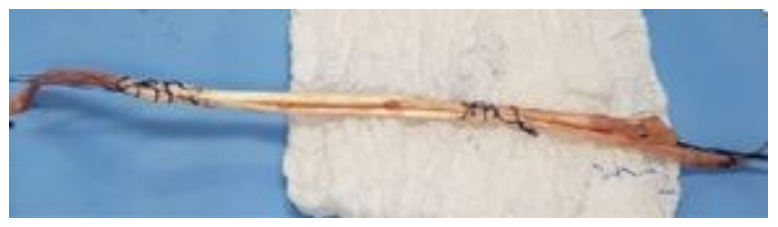

Figure 3 
The grafts are attached with simple suture using absorbable thread.

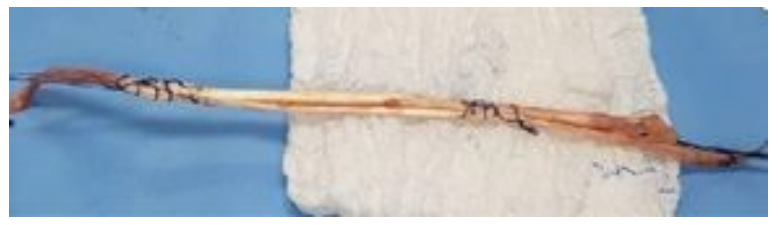

\section{Figure 3}

The grafts are attached with simple suture using absorbable thread.

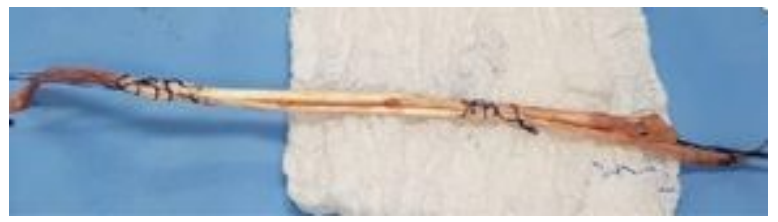

\section{Figure 3}

The grafts are attached with simple suture using absorbable thread.
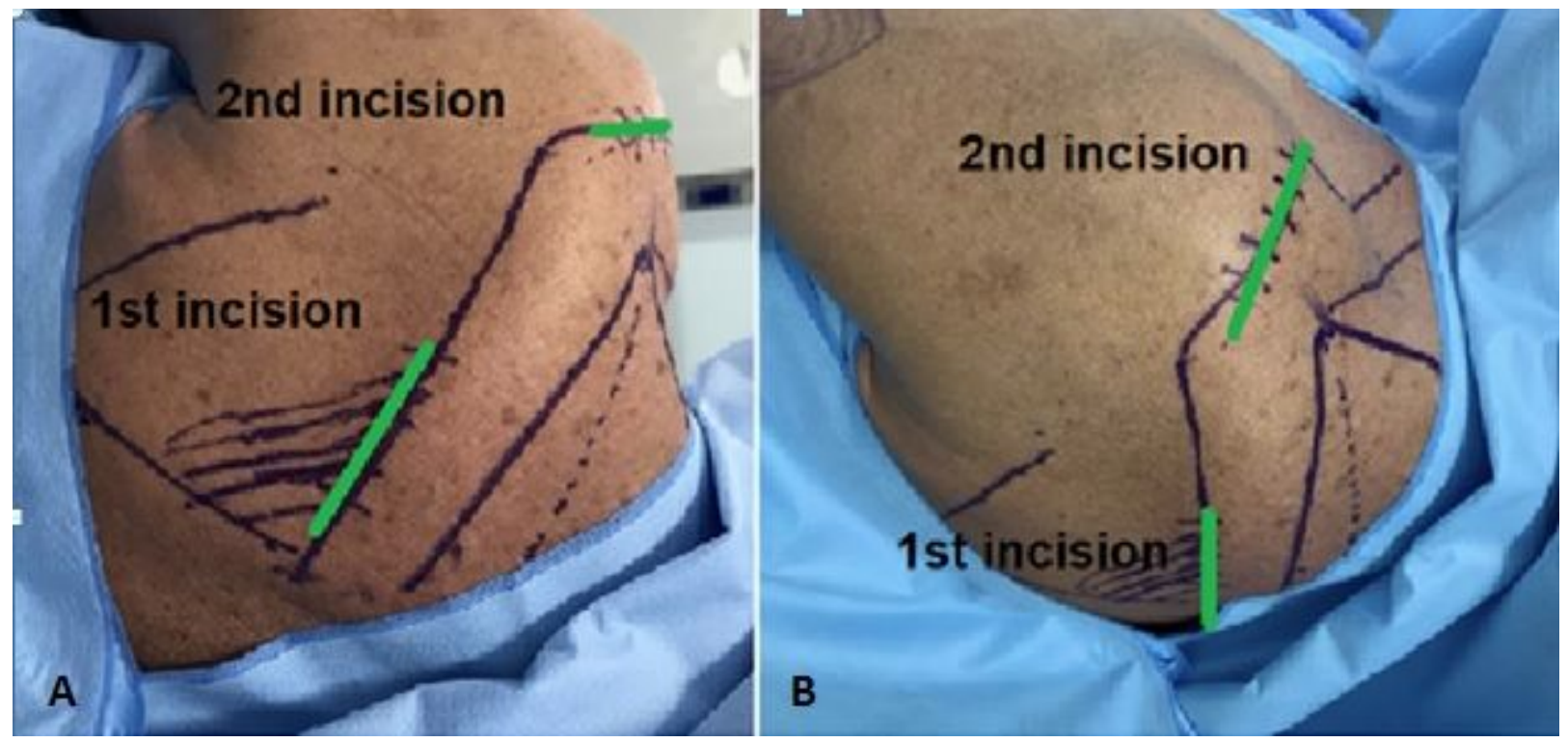

Figure 4

Intraoperative photo of the left shoulder showing the marks where the incisions are made. (A) An incision of $4 \mathrm{~cm}$ in the middle third of the scapular spine. (B) A saber-cut incision under the lateral acromial margin. 

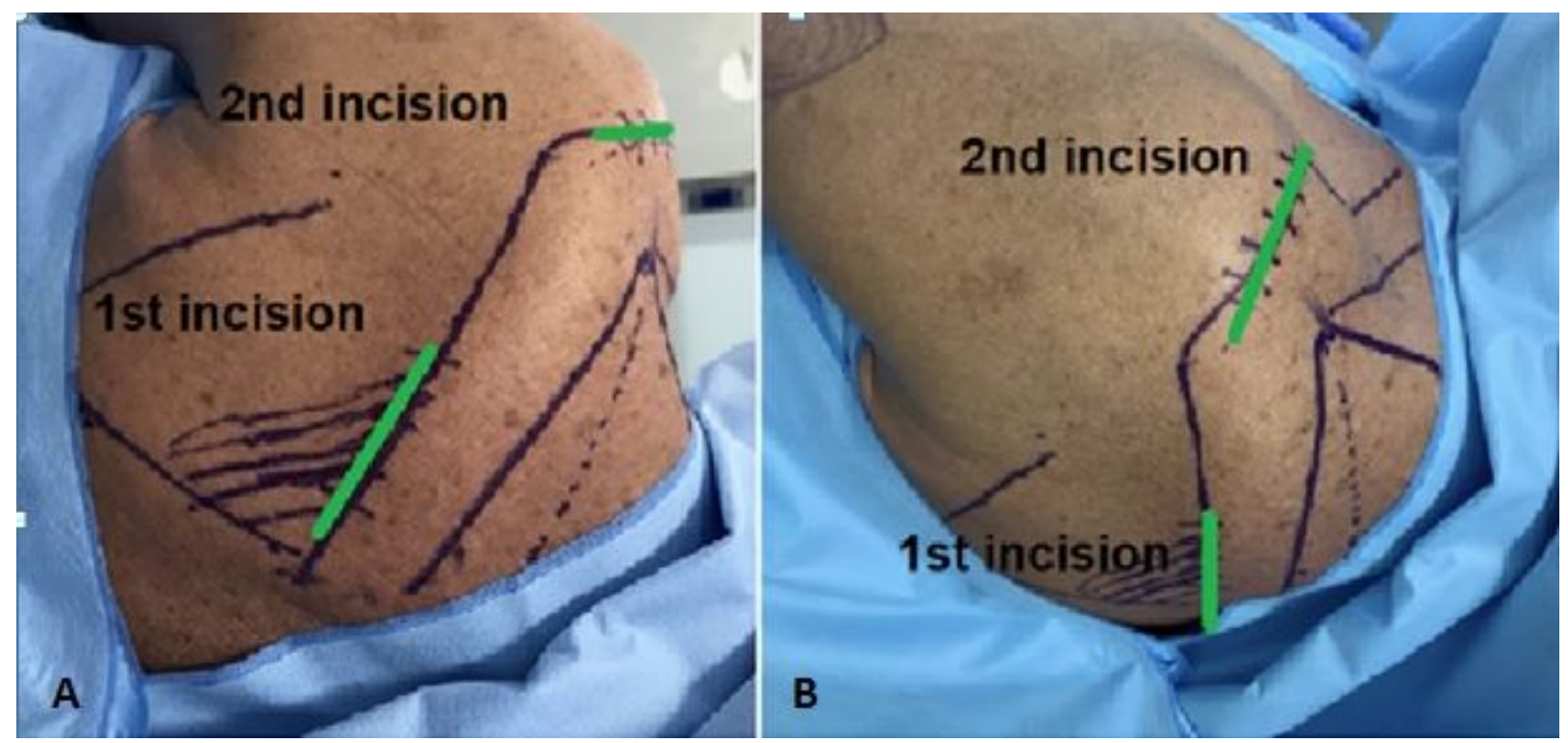

\section{Figure 4}

Intraoperative photo of the left shoulder showing the marks where the incisions are made. (A) An incision of $4 \mathrm{~cm}$ in the middle third of the scapular spine. (B) A saber-cut incision under the lateral acromial margin.

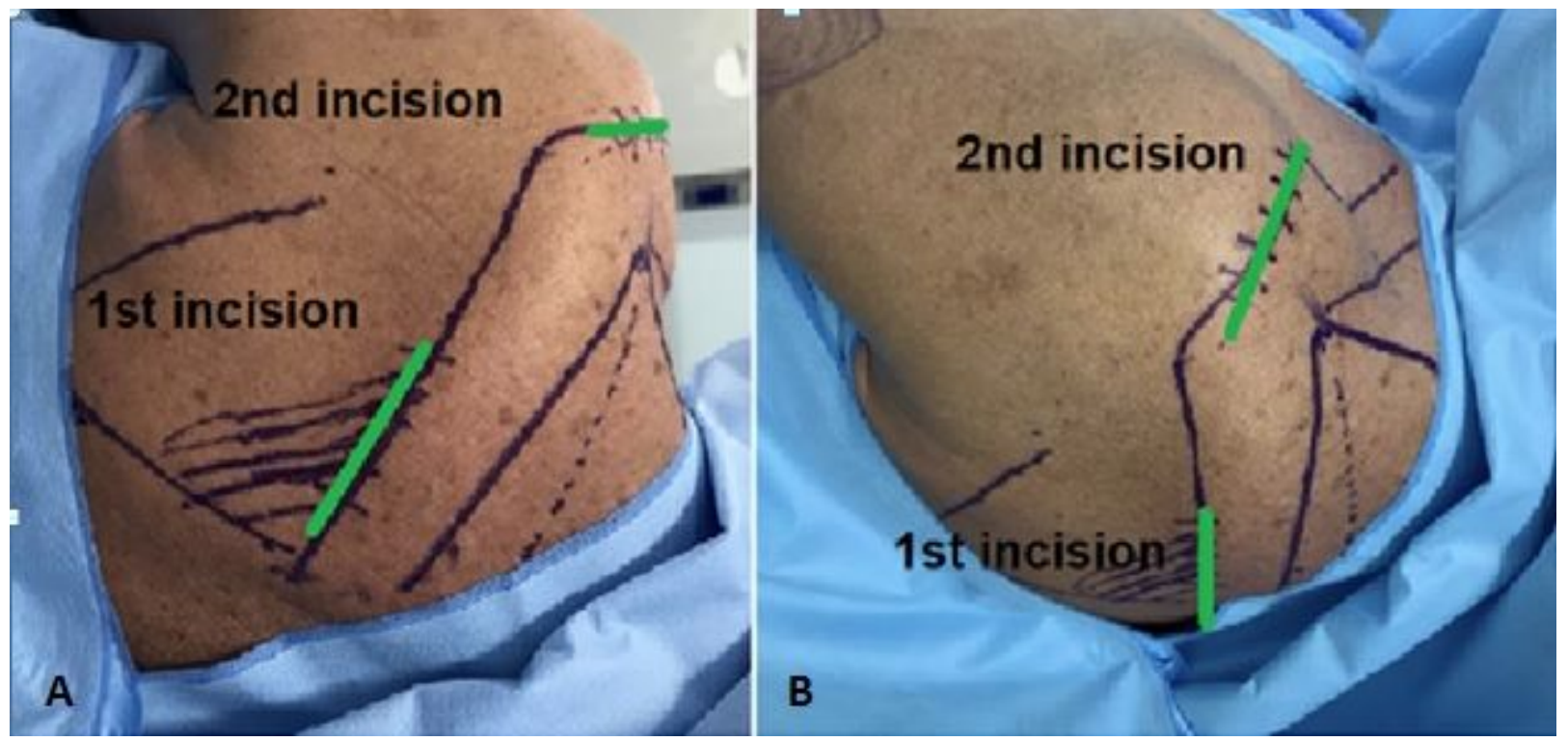

\section{Figure 4}

Intraoperative photo of the left shoulder showing the marks where the incisions are made. (A) An incision of $4 \mathrm{~cm}$ in the middle third of the scapular spine. (B) A saber-cut incision under the lateral acromial margin. 


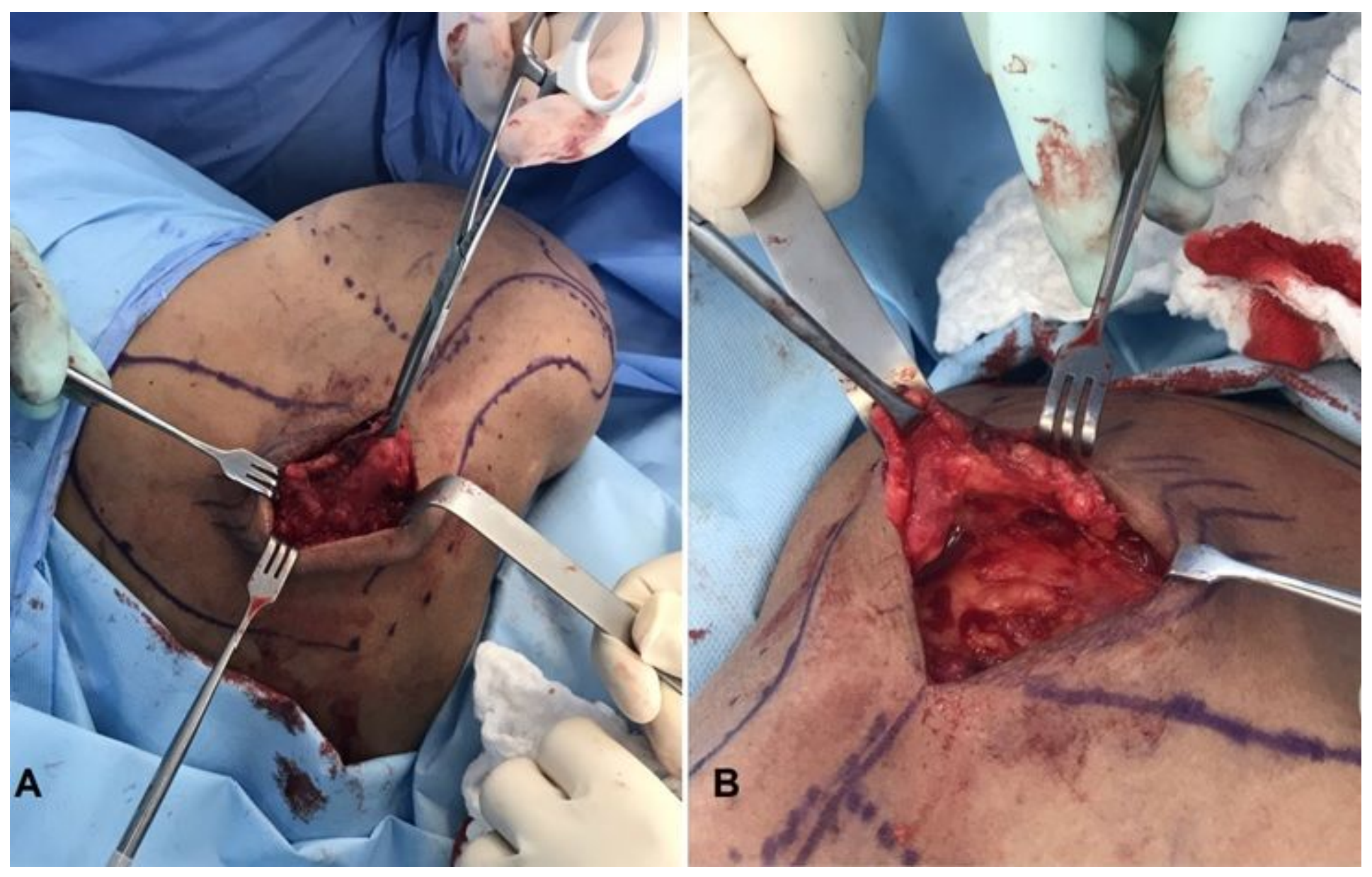

Figure 5

(A) Back view of the first incision showing the dissection of the LT. (B) Bottom view of the LT flap. LT: lower trapezius 


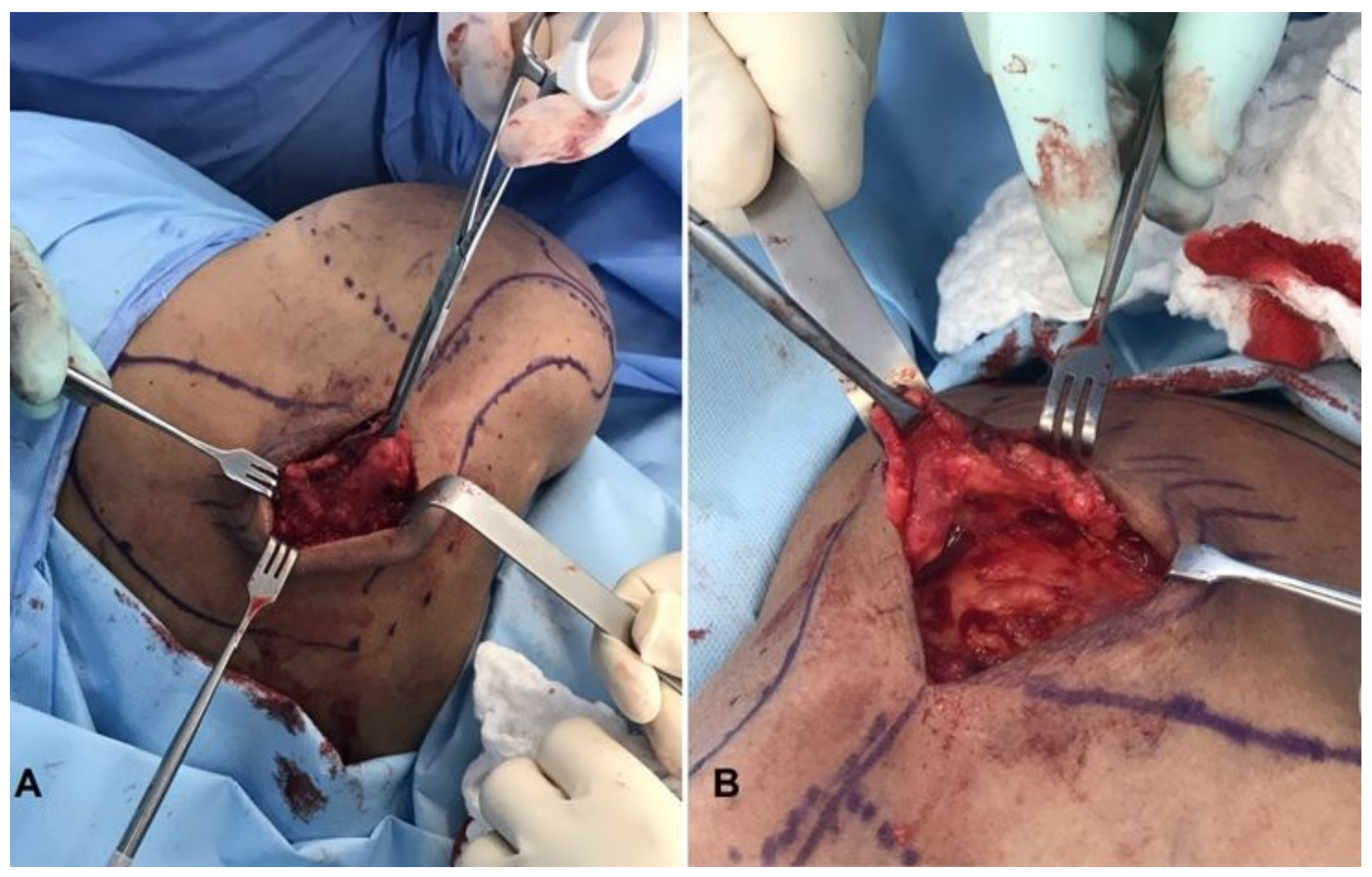

Figure 5

(A) Back view of the first incision showing the dissection of the LT. (B) Bottom view of the LT flap. LT: lower trapezius 


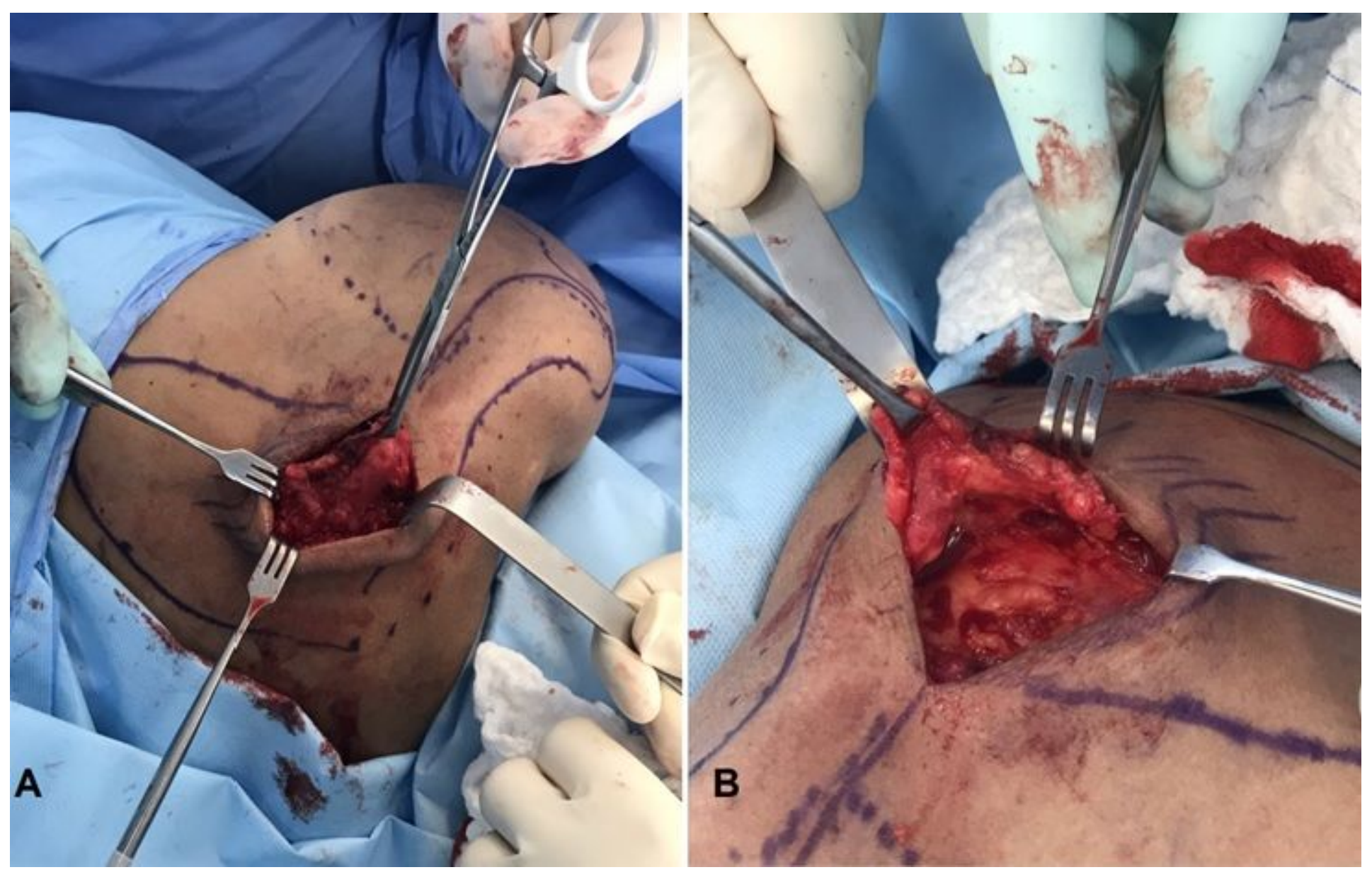

Figure 5

(A) Back view of the first incision showing the dissection of the LT. (B) Bottom view of the LT flap. LT: lower trapezius

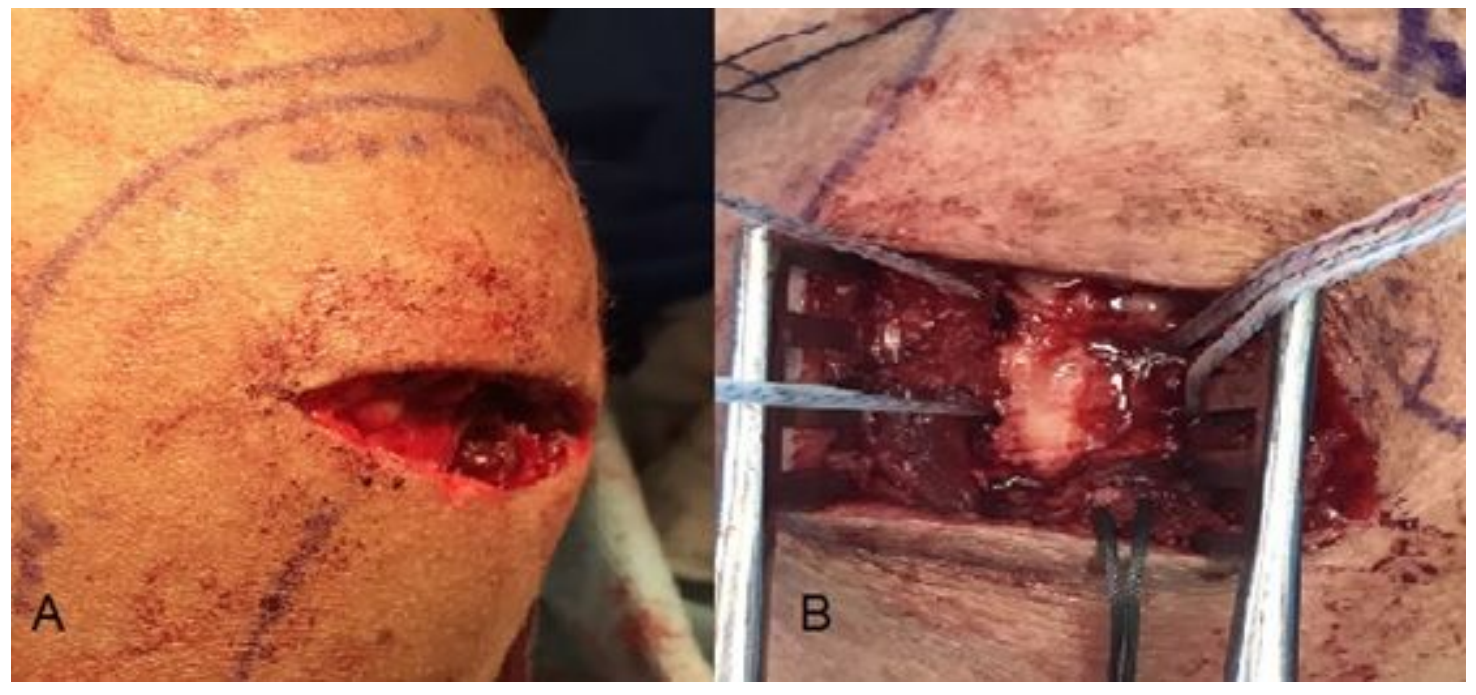

Figure 6

(A) Back view of the second incision. (B) Upper view of the second incision with the anchors placed at the footprint of the infraspinatus tendon. 


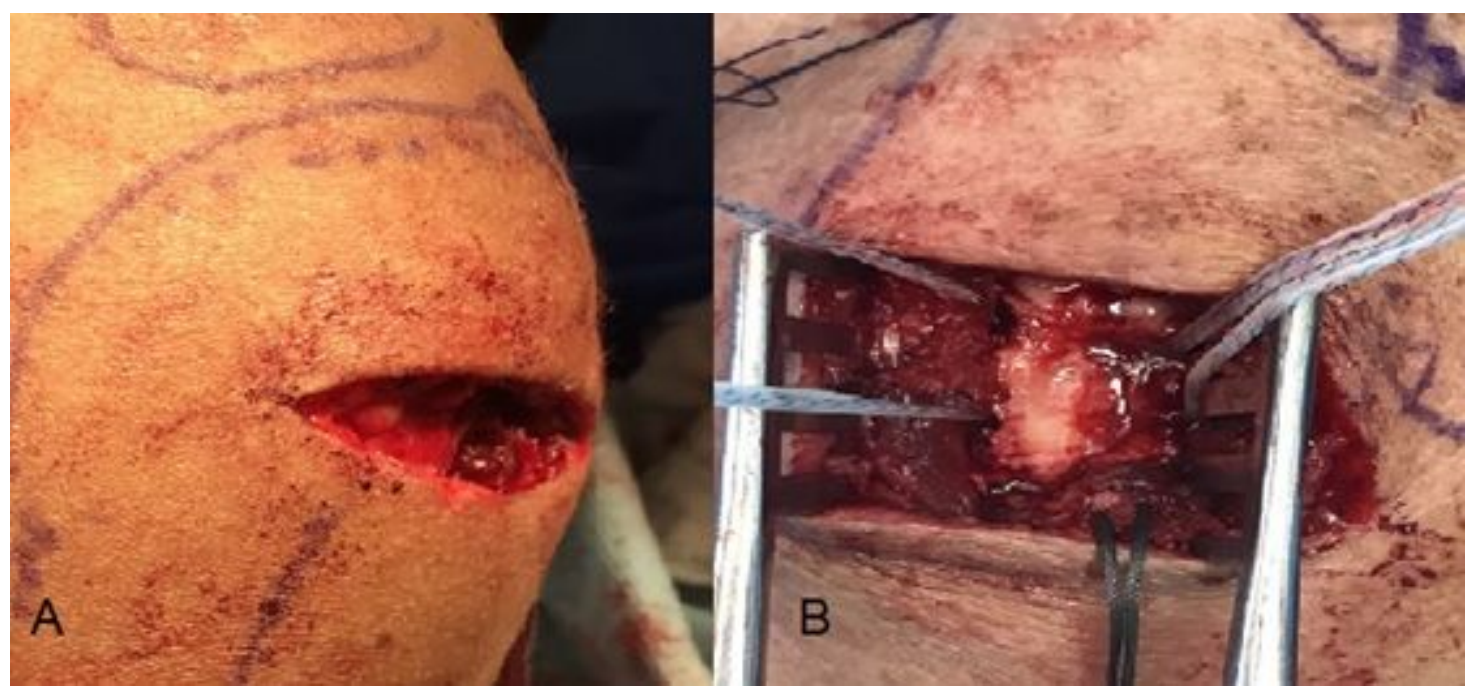

Figure 6

(A) Back view of the second incision. (B) Upper view of the second incision with the anchors placed at the footprint of the infraspinatus tendon.

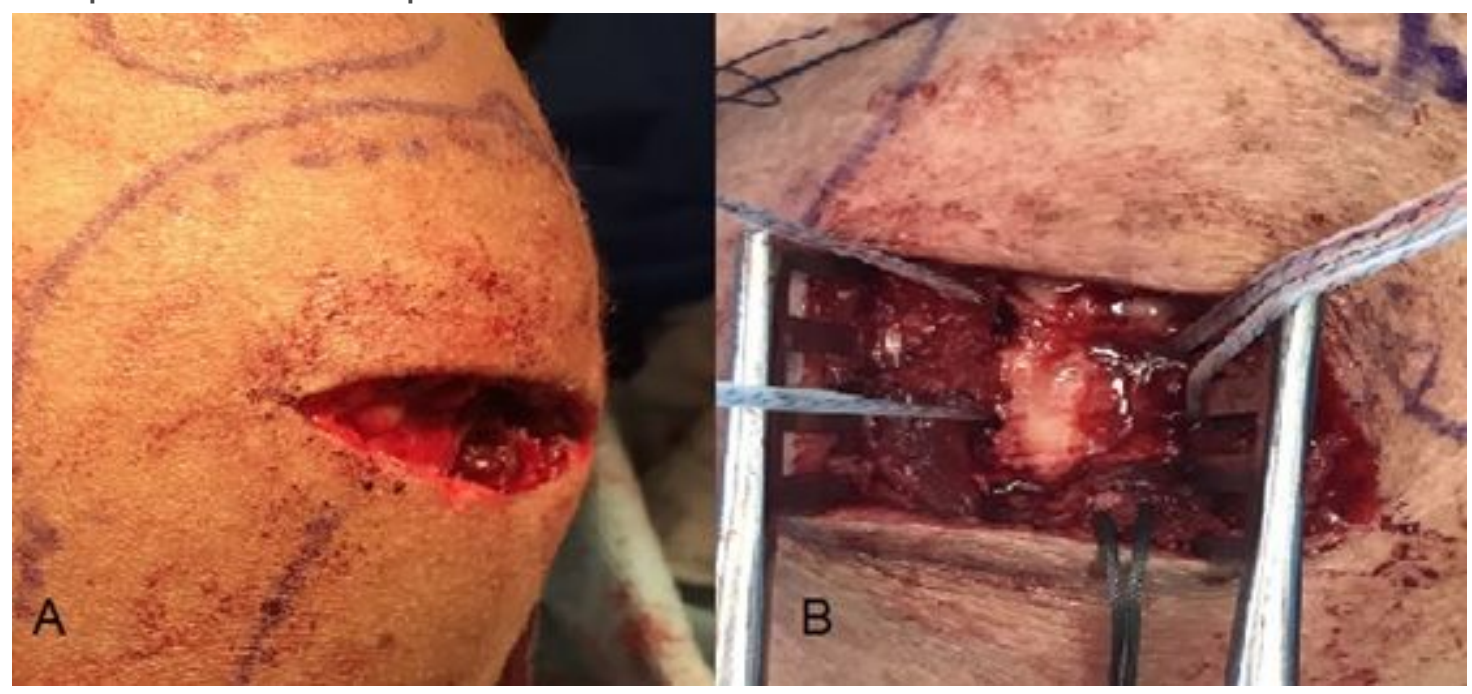

Figure 6

(A) Back view of the second incision. (B) Upper view of the second incision with the anchors placed at the footprint of the infraspinatus tendon. 


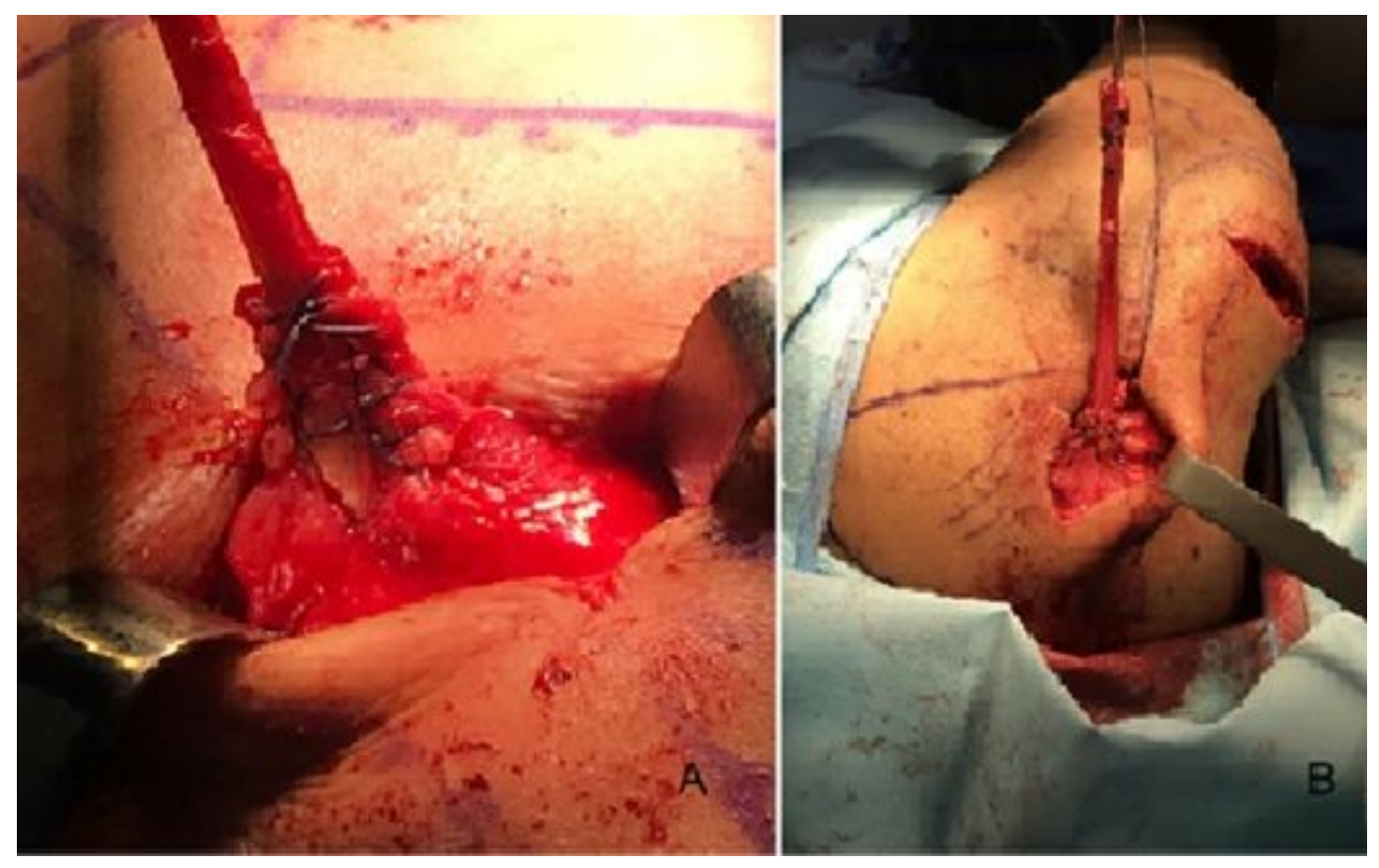

Figure 7

(A) Suture of the graft to the LT tendon. (B) Enlarged view showing the graft attached to the LT. LT: lower trapezius

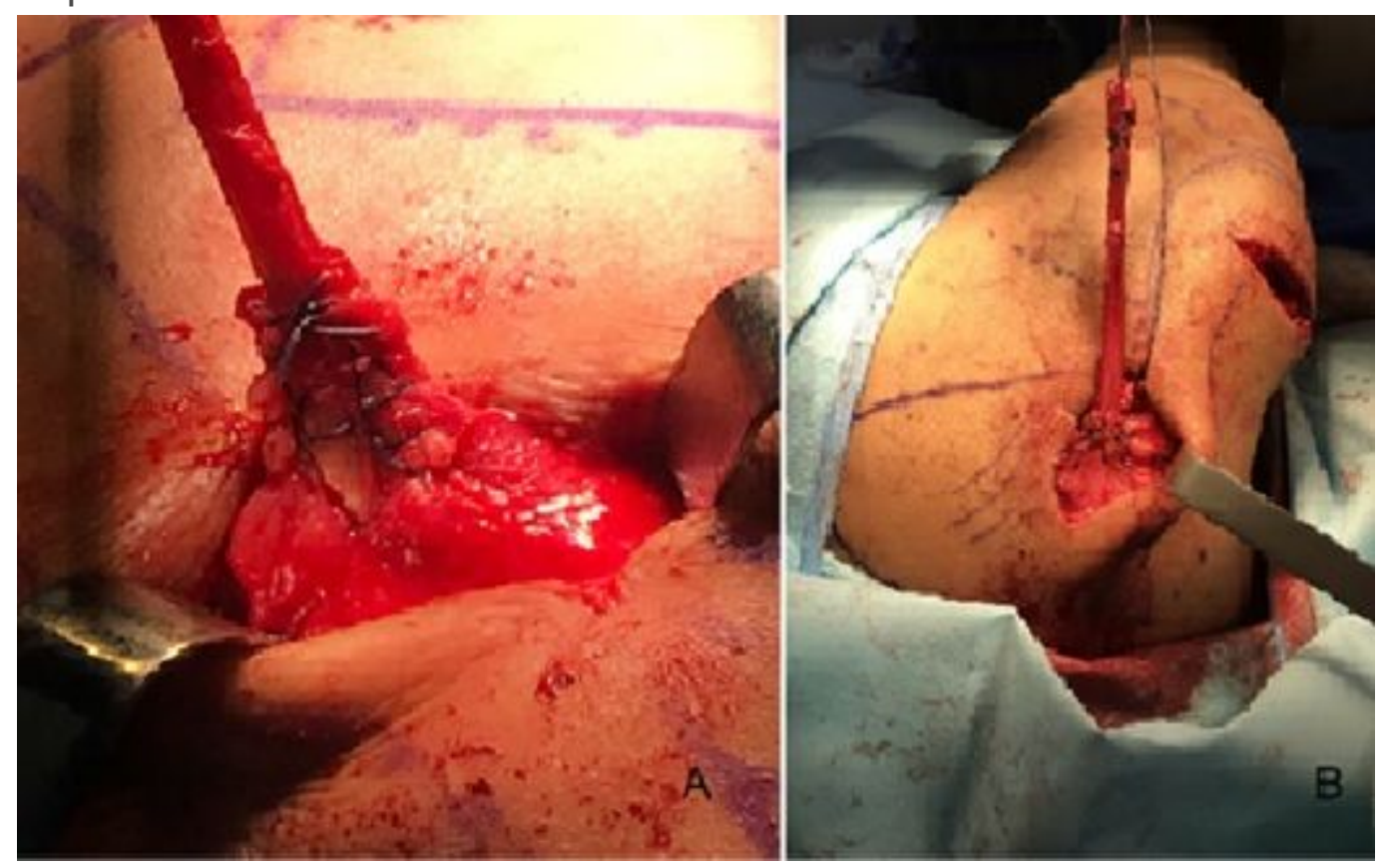

Figure 7

(A) Suture of the graft to the LT tendon. (B) Enlarged view showing the graft attached to the LT. LT: lower trapezius 


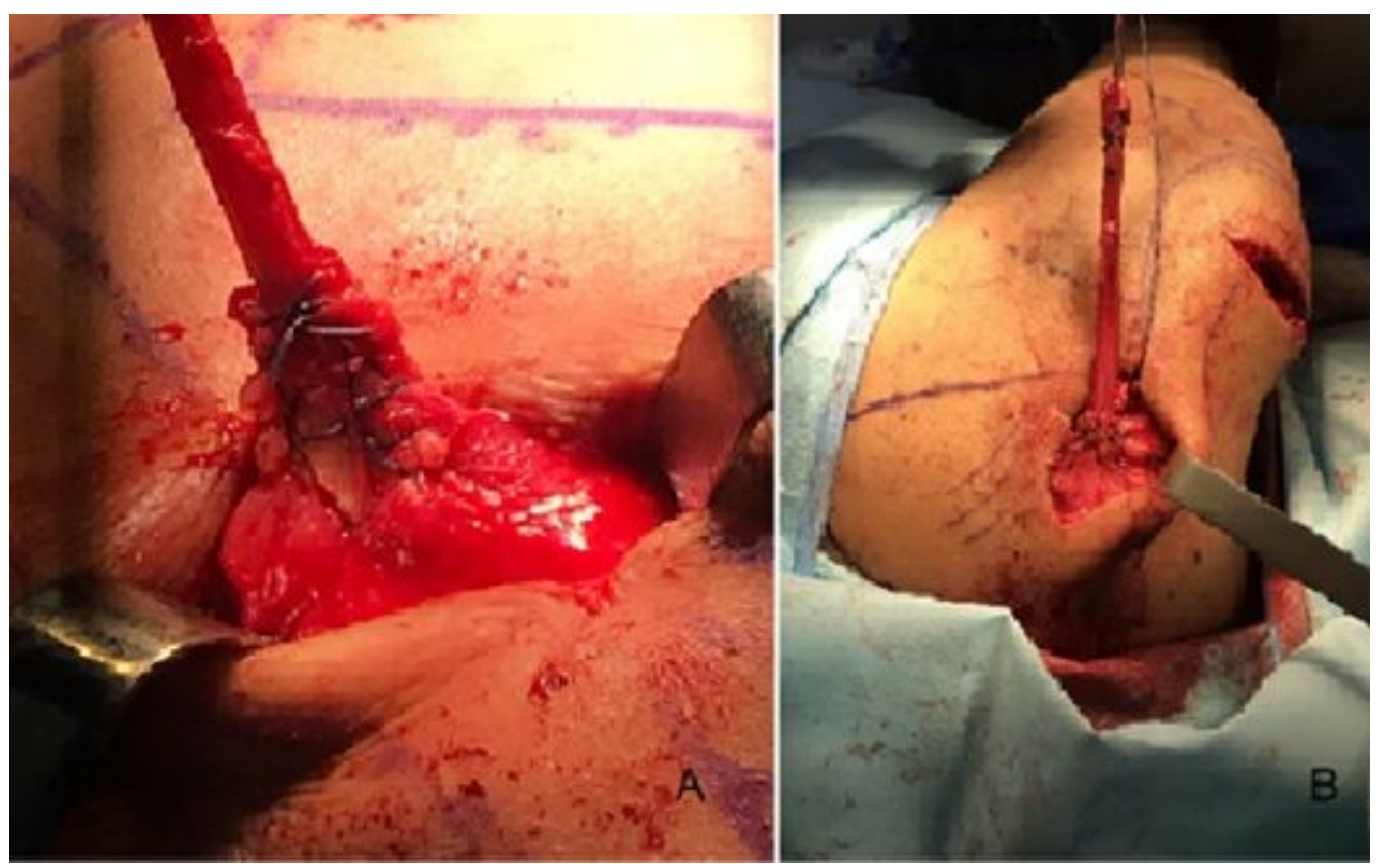

Figure 7

(A) Suture of the graft to the LT tendon. (B) Enlarged view showing the graft attached to the LT. LT: lower trapezius

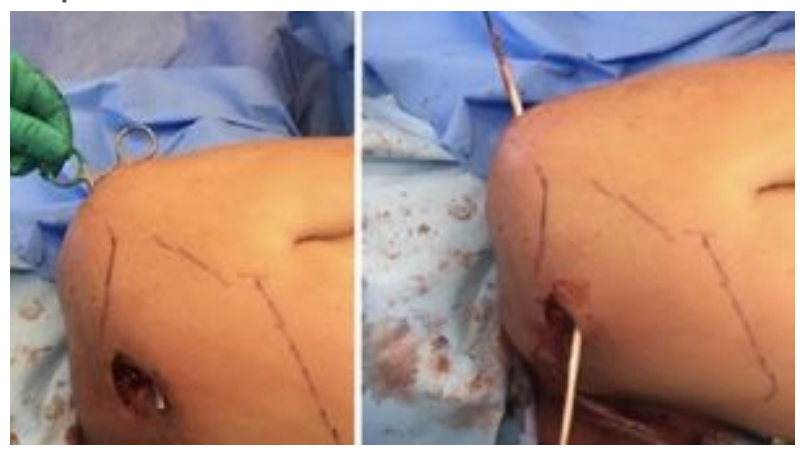

Figure 8

Long forceps passage from the anterior to the posterior.

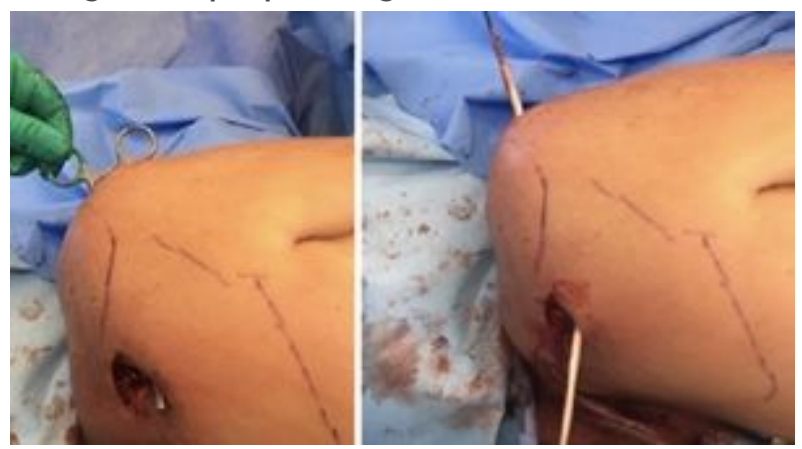

Figure 8

Long forceps passage from the anterior to the posterior. 

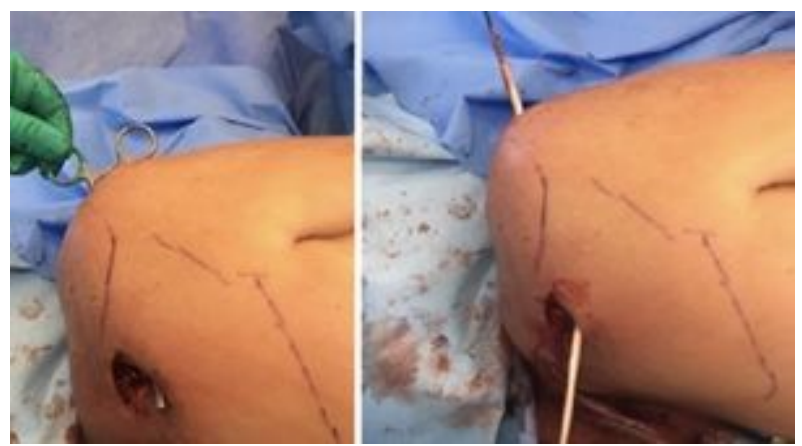

Figure 8

Long forceps passage from the anterior to the posterior.

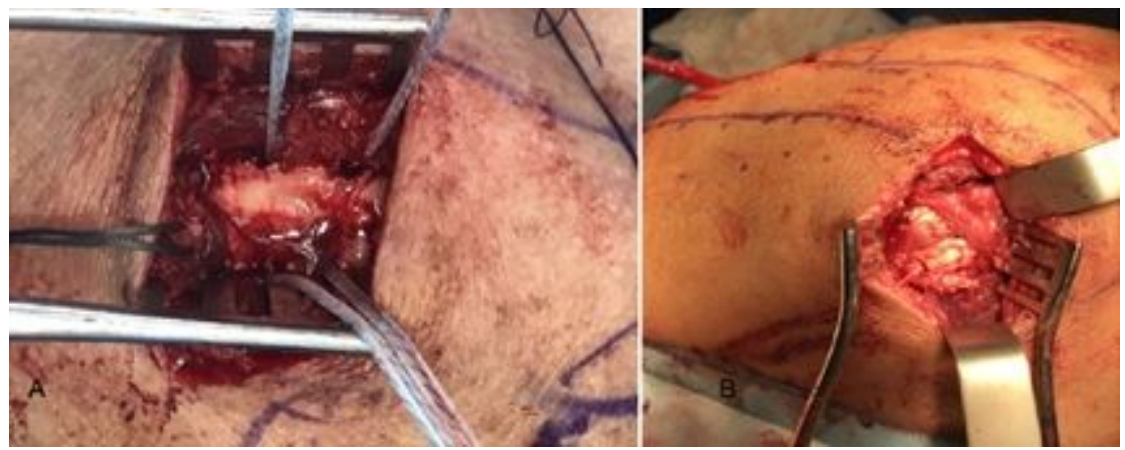

Figure 9

(A) View of the footprint of the infraspinatus tendon totally uncovered. (B) Coverage area with graft after the repair.

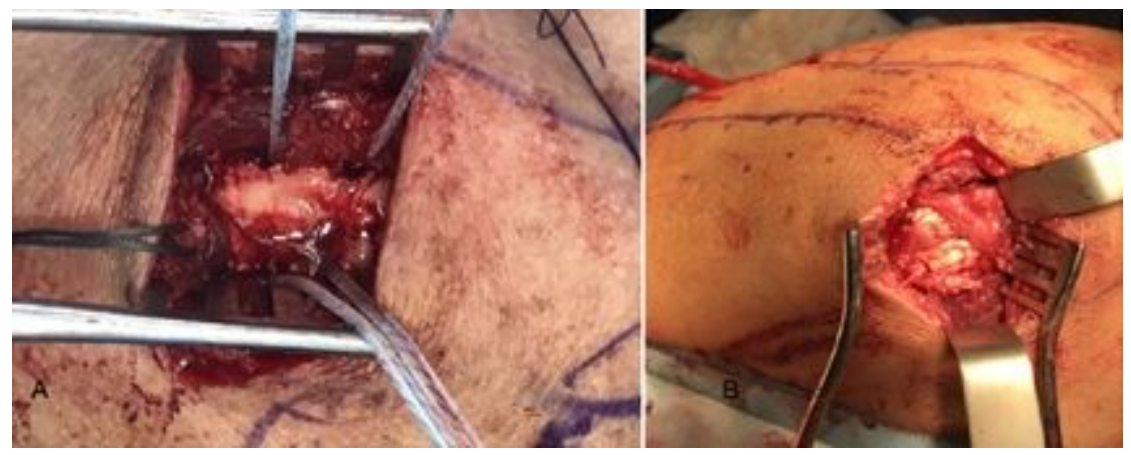

Figure 9

(A) View of the footprint of the infraspinatus tendon totally uncovered. (B) Coverage area with graft after the repair. 


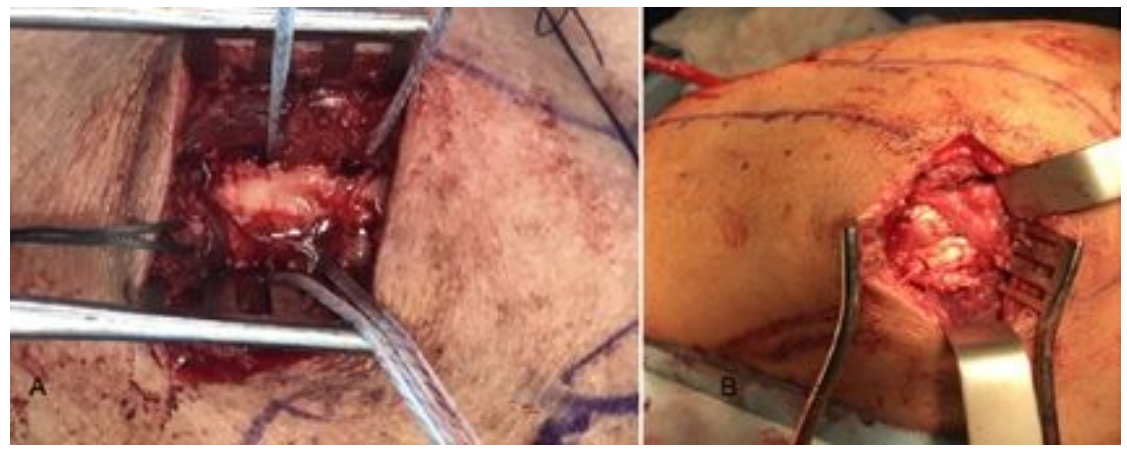

Figure 9

(A) View of the footprint of the infraspinatus tendon totally uncovered. (B) Coverage area with graft after the repair.

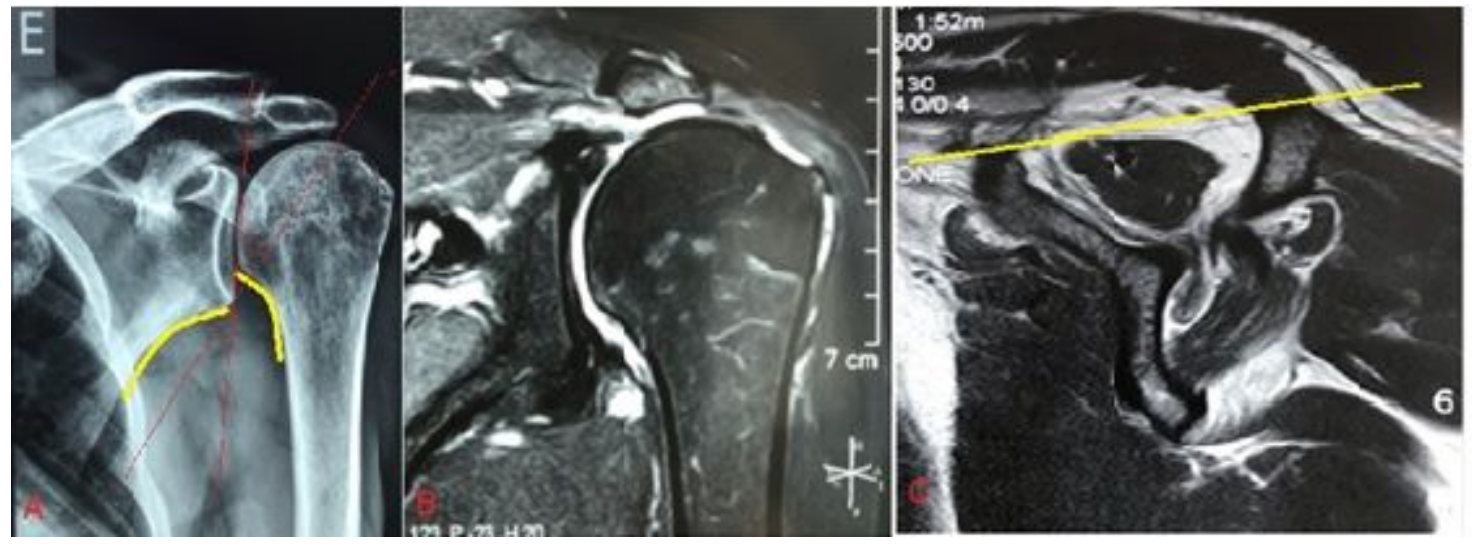

Figure 10

(A) A decrease in the subacromial space $=2 \mathrm{~mm}$. (B) A massive injury of the supraspinatus tendon. (C) Tangent sign showing degeneration of the supraspinatus musculature.

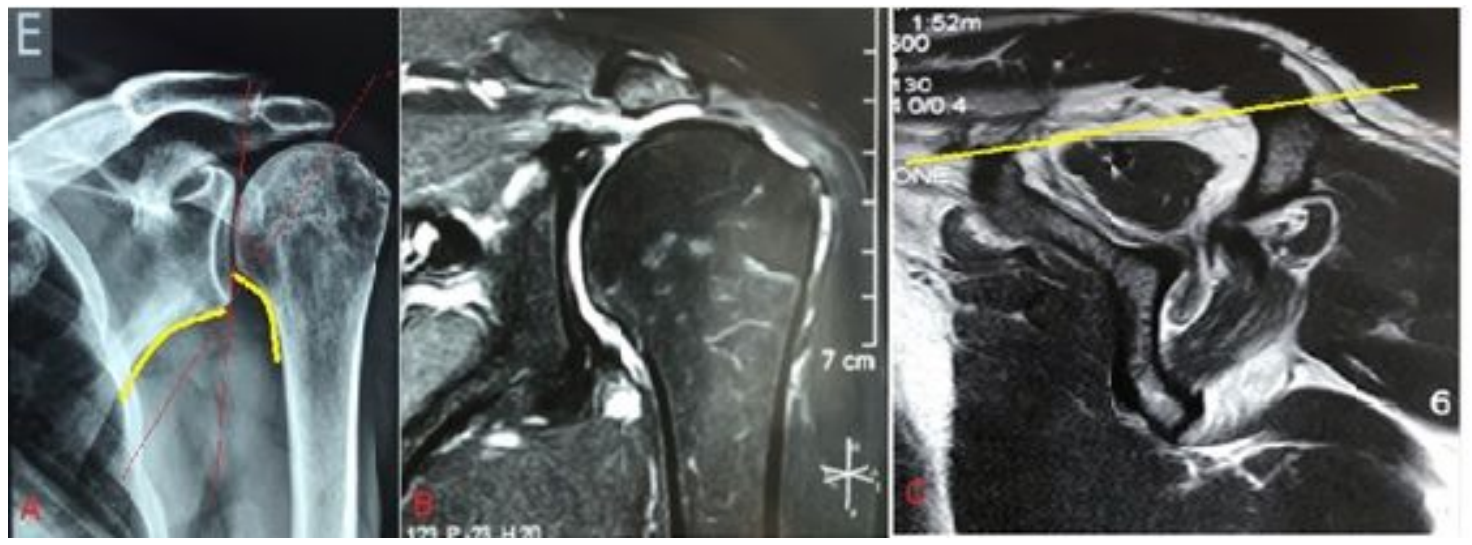

Figure 10

(A) A decrease in the subacromial space $=2 \mathrm{~mm}$. (B) A massive injury of the supraspinatus tendon. (C) Tangent sign showing degeneration of the supraspinatus musculature. 


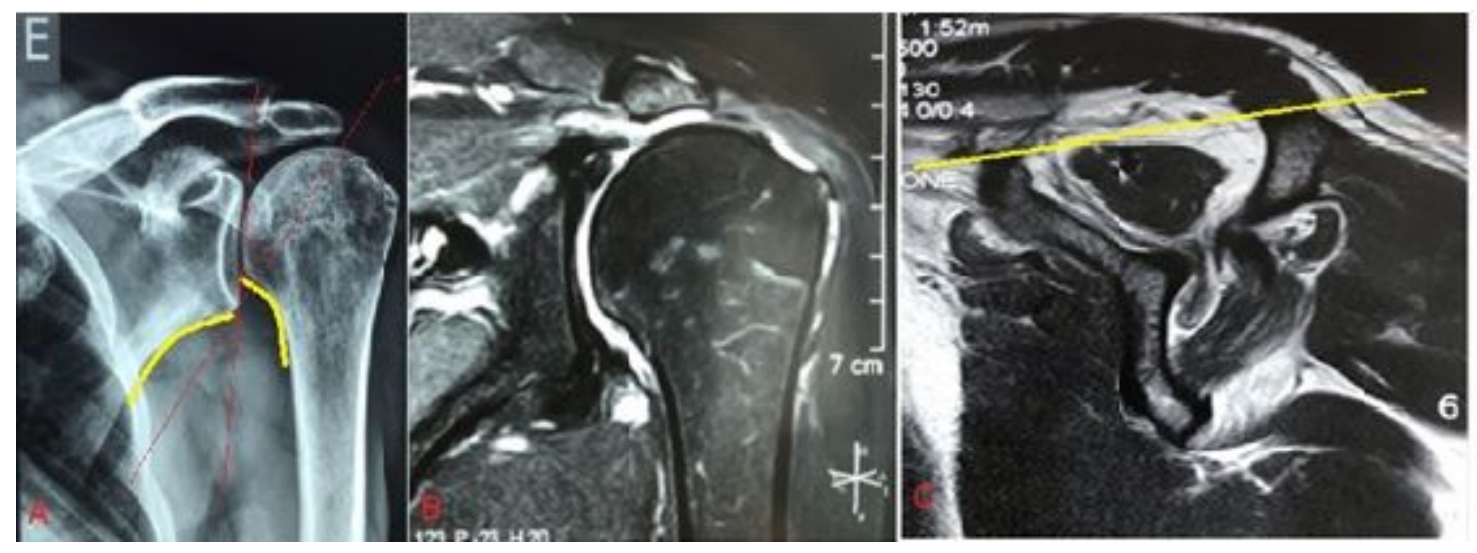

Figure 10

(A) A decrease in the subacromial space $=2 \mathrm{~mm}$. (B) A massive injury of the supraspinatus tendon. (C) Tangent sign showing degeneration of the supraspinatus musculature.

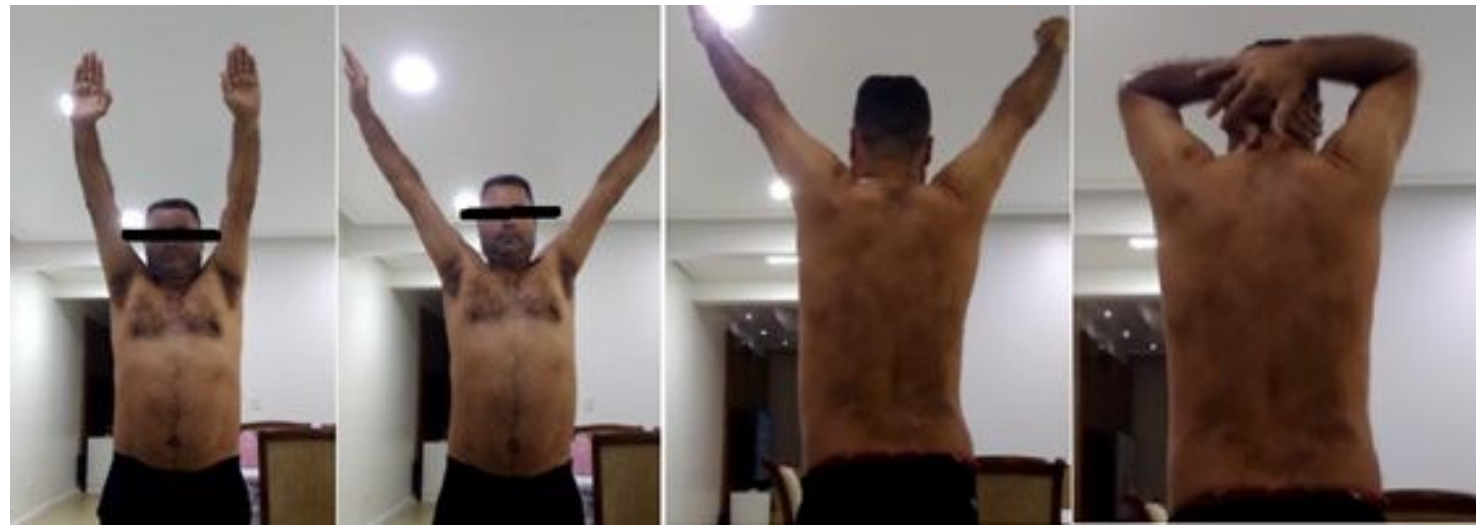

Figure 11

Demonstration of patient's motion range at his six-month follow-up evaluation.

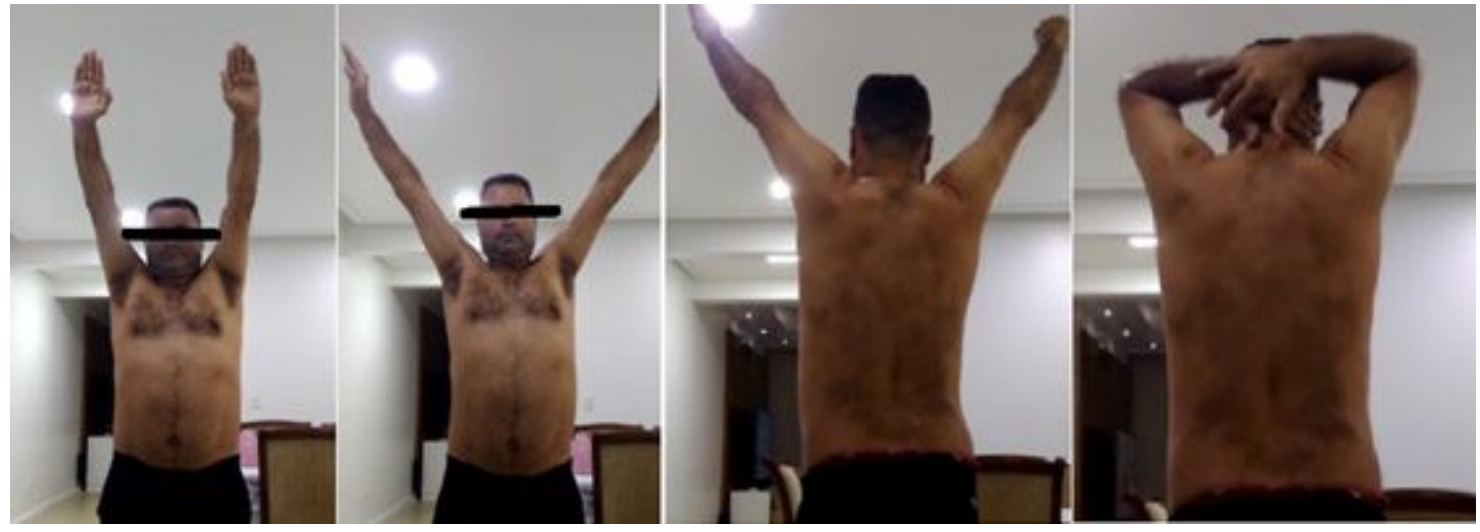

Figure 11

Demonstration of patient's motion range at his six-month follow-up evaluation. 


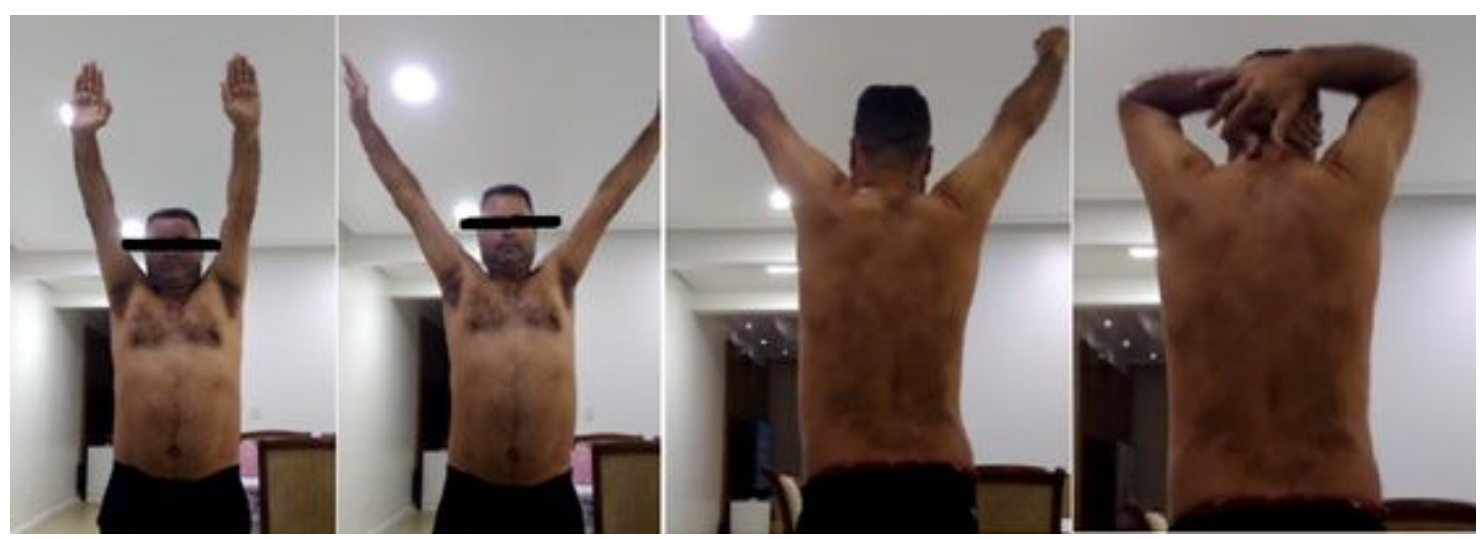

Figure 11

Demonstration of patient's motion range at his six-month follow-up evaluation. 